\title{
A rare case of ovarian thecoma in a postmenopausal woman
}

\author{
Yashwant S. Kulkarni, Aniket S. Kakade*, Bhumija A. Singh
}

Department of Obstetrics \& Gynecology, Bharati Vidyapeeth Deemed University Medical College, Bharati Hospital \& Research Centre, Dhankawadi, Pune - 411043. Maharashtra, India

Received: 16 November 2013

Accepted: 15 December 2013

\section{*Correspondence:}

Dr. Aniket S. Kakade,

E-mail: anikeeet@yahoo.co.in

(C) 2014 Kulkarni YS et al. This is an open-access article distributed under the terms of the Creative Commons Attribution Non-Commercial License, which permits unrestricted non-commercial use, distribution, and reproduction in any medium, provided the original work is properly cited.

\begin{abstract}
Thecomas are very rare solid tumors of ovary and are a type of sex-cord stromal tumors. They account for approximately $0.5 \%-1 \%$ of primary ovarian tumors. We report a rare incidence of this tumor which presented in a postmenopausal woman. She presented with abdominal discomfort and underwent an ultrasonography revealing a solid ovarian tumor. She underwent a total abdominal hysterectomy with bilateral salpingo-oophorectomy. Histopathological examination showed benign thecoma. Hence it is important to keep this benign condition in mind when dealing with solid ovarian tumors in postmenopausal woman.
\end{abstract}

Keywords: Thecoma, Postmenopausal, Solid ovarian tumor

\section{INTRODUCTION}

Thecomas are rare solid sex-cord stromal ovarian tumors, and account for approximately $0.5 \%-1 \%$ of primary ovarian lesions. ${ }^{1,2}$ Although Thecomas are often mixed with fiber components (then called 'fibrothecomas'), thecomas and fibrothecomas are now considered to originate from the ovarian medulla, with a different etiology from fibromas, which originate from the cortex. ${ }^{3}$ The incidence of solid ovarian tumors in postmenopausal women is around $18 \% .^{4}$

We present a rare case of thecoma in a postmenopausal woman diagnosed incidentally on ultrasonography done for abdominal pain. Ultrasonography pointed out towards a benign solid unilateral ovarian tumor with poor vascularity. The patient did not have any other symptoms suggestive of hormonal secretion. Patient was counseled regarding the benign nature of the tumor and opted for surgical removal and underwent total hysterectomy with bilateral salpingo-oophorectomy.

\section{CASE REPORT}

A 75 years woman was referred to gynecological outpatient department with complaints of pain in the abdomen with an ultrasound report suggestive of solid ovarian tumor. She was admitted in the department of Medicine for complaints of generalized weakness and abdominal discomfort. The pain was dull aching in the supra-pubic region. She had no associated bowel or bladder complaints. She was on medications for hypertension since 25years. There was no other medical or surgical history. She had four vaginal deliveries and underwent puerperal tubal ligation 45 years back. She was postmenopausal since 15 years.

Her pulse was 80 beats/minutes, blood pressure was $130 / 80 \mathrm{mmHg}$, she did not have pallor and her supraclavicular nodes were not palpable. Her abdomen was soft, non-tender and there was no ascites. Liver and spleen were not palpable. On per speculum examination cervix and vagina was atrophic. On per vaginal examination a hard mass of $8 \mathrm{cms}$ was felt in the right fornix which had smooth surface and was mobile. It was 
not attached to the uterus. Uterus was small and the left fornix was clear.

Her hemoglobin was: 11.5 gram\%, CA-125 was 7.90 $\mathrm{U} / \mathrm{ml}$. Ultrasonography showed well defined heterogeneous mass measuring 6.5 x 5.7 x $5.4 \mathrm{cms}$ with few specks of calcification within and hypo echoic areas within suggestive of area of degeneration. Peripheral vascularity was noted on color flow study. The lesion was completely separate from the uterus. The other ovary and uterus were normal. Endometrial thickness was $3 \mathrm{~mm}$. There was minimal fluid in the pelvis. It was mostly suggestive of a benign pathology.

In view of the benign radiological findings of the mass the patient and relatives were counseled regarding expectant management and close follow-up with ultrasonography. The patient and her relatives opted for surgical management as she resides in their native place with minimal access to medical care.

The abdomen was accessed via transverse supra pubic incision. There was a solid white mass in the left ovary which was have one twist of the pedicle and hence was displaced on the right side. It was $6 \times 6 \mathrm{cms}$ arising from right ovary and appeared to involve the ovary completely (Figure 1). The left ovary and uterus were atrophic. Minimal omental adhesions were present on the right side. There were no para-aortic nodes palpable and the omentum appeared normal. Liver and other peritoneal structures were not involved.

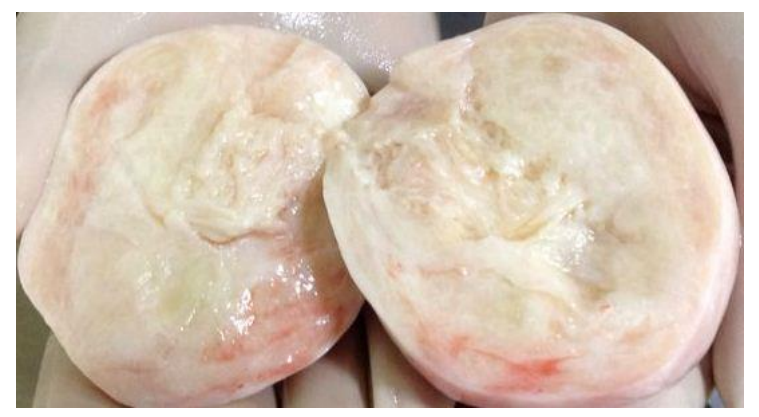

Figure 1: Cut section showing solid white tumor with some yellowish areas.

A total abdominal hysterectomy with bilateral salpingooophorectomy was performed. Histopathology showed: a large whitish, encapsulated nodular mass of $6 \mathrm{~cm}$ length. The capsular surface showed congested blood vessels. On cut section it showed homogenous whitish glistening appearance with some yellowish areas. On microscopy it showed spindle shaped tumor cells arranged in tight fascicles (Figure 2). Ample eosinophilic cytoplasm and vesicular nuclei are seen. There was no evidence of granuloma or atypia or malignancy.

Post-operative course of the patient was uneventful. She was discharged on day seven after suture removal.

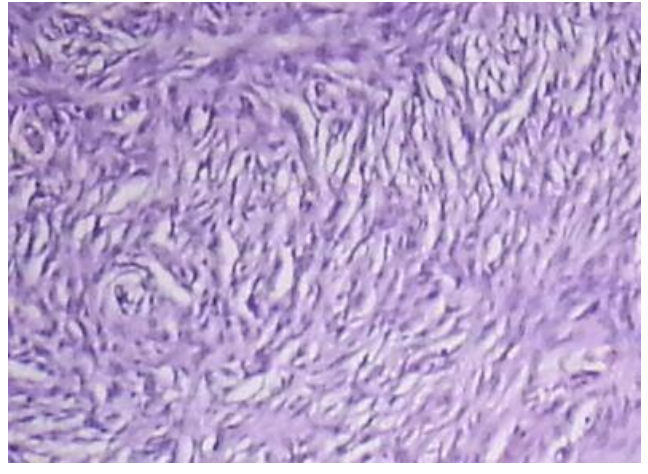

Figure 2: Spindle shaped tumor cells arranged in tight fascicles.

\section{DISCUSSION}

Ovarian thecoma (Theca cell tumor) is a solid, stromal tumor composed of lipid-containing cells resembling those of the theca interna and may have a variable component of fibroblasts. ${ }^{5}$ Thecomas predominantly affects postmenopausal women with a mean age of 59 years. 3,6

More than $90 \%$ of thecomas show immuno-reactivity with $\alpha$-inhibin. Symptoms related to estrogen secretion including postmenopausal bleeding, endometrial hyperplasia and endometrial cancer occur in more than half of the patients. ${ }^{1,5}$

Cystic degeneration and varying degrees of edema can be observed in larger lesions ${ }^{6}$. Generally, ovarian thecoma is considered a benign disease, although some anecdotal malignant cases have been reported. ${ }^{2}$

The neoplasms can be divided into typical, luteinized, and calcified forms. ${ }^{5}$

Typical thecoma: the cells have uniform, bland, oval to spindle-shaped nuclei with abundant, pale, vacuolated lipid-rich cytoplasm. Hyaline plaques may be present in fibroma-like areas. Reticulin surrounds individual tumor cells.

Luteinized thecoma (partly luteinized theca cell tumor): luteinized thecoma, more accurately described as partly luteinized thecoma because the majority of the stromal cells are not luteinized in most examples. These tumors produce significant quantities of steroid hormones. Approximately one half the cases are estrogenic, and $11 \%$ of cases are virilizing. Histologically they contain clusters of lutein cells with pale, eosinophilic, or vacuolated cytoplasm usually in fibroma-like background. They may be associated with sclerosing peritonitis.

Calcified thecoma: in contrast to fibroma, thecomas rarely are calcified. Most patients are young and usually present with menstrual abnormalities. These are benign tumors. 
The reported case is a rare occurrence of thecoma in postmenopausal woman having no symptoms except vague abdominal discomfort. The tumor was diagnosed incidentally on screening ultrasonography. Though the benign nature of the cyst was diagnosed on ultrasonography the patient opted for a surgical removal which revealed a thecoma. The vague discomfort that the patient had might be due to single twist torsion of the tumor.

With increase in the diagnosis of postmenopausal ovarian tumors in asymptomatic woman on ultrasonography done for other medical reasons, a differential diagnosis of this benign solid tumor should be kept in mind. Surgical excision of these tumors is curative.

\section{ACKNOWLEDGEMENTS}

The authors would like to thank Dr Girija Wagh, Professor \& Head in Obstetrics \& Gynecology, Dr Renuka Hapse, Assistant Professor in Radiology, Dr Manjiri Karandikar, Professor in Pathology and Dr Ravi Swami, Assistant Professor in Pathology for their help in management of the patient.

Funding: No funding sources Conflict of interest: None declared

Ethical approval: Not required

\section{REFERENCES}

1. Chen VW, Ruiz B, Killeen JL, Timothy RC, Wu XC, Catherine NC. Pathology and classification of ovarian tumors. Cancer. 2003;97:2631-42.

2. Zhang H, Zhang GF, Wang TP, Zhang H. Value of 3.0 diffusion-weighted imaging in discriminating thecoma and fibrothecoma from other adnexal solid masses. Journal of Ovarian Research. 2013;6:58.

3. Nocito AL, Sarancone S, Bacchi C, Tellez T. Ovarian thecoma: clinicopathological analysis of 50 cases. Ann Diagn Pathol. 2008;12(1):12-6.

4. Annaiah TK, Reynolds SF, Lopez C. Histology and prevalence of ovarian tumors in postmenopausal women: is follow-up required in all cases? J Obstet Gynecol. 2012;32(3):267-70.

5. Roth LM. Recent advances in the pathology and classification of ovarian sex cord- stromal tumors. Int J Gynecol Pathol. 2006;25(3):199-215.

6. Li X, Zhang W, Zhu G, Sun C, Liu Q, Shen Y. Imaging features and pathologic characteristics of ovarian thecoma. J Comput Assist Tomogr. 2012;36(1):46-53.

DOI: $10.5455 / 2320-1770$. ijrcog20140350

Cite this article as: Kulkarni YS, Kakade AS, Singh BA. A rare case of ovarian thecoma in a postmenopausal woman. Int J Reprod Contracept Obstet Gynecol 2014;3:242-4. 